\title{
Radiographic assessment of maxillary sinus lateral wall thickness in edentulous posterior maxilla
}

\author{
Amir Kiakojori ${ }^{1}$, Seyede Parisa Motamedi Nasab ${ }^{2}$, Farida Abesi ${ }^{3}$, Hemmat Gholinia ${ }^{4}$
}

${ }^{1}$ DDS, MS, Assistant Professor, Oral Health Research Center, Institute of Health, Babol University of Medical Sciences, Babol, Iran

${ }^{2}$ DDS, Dentist, Student Research Committee, Babol University of Medical Sciences, Babol, Iran

${ }^{3}$ DDS, MS, Associate Professor, Dental Materials Research Center, Institute of Health, Babol University of Medical Sciences, Babol, Iran

${ }^{4}$ Master of Science in Statistics, Health Research Institute, Babol University of Medical Sciences, Babol, Iran

\section{Type of article: Original}

\begin{abstract}
Background and aim: Given the importance of evaluating the maxillary sinus lateral wall thickness (LWT) to avoid complications during surgery, the aim of this study was to examine LWT as well as the effect of residual ridge height $(\mathrm{RH})$, edentulous region, type of edentulism, age and gender on it.

Methods: In this cross-sectional study conducted in 2016, 150 samples of the CBCT imaging archives of the Oral and Maxillofacial Radiology Clinic in Babol, Iran, were evaluated retrospectively. In the coronal section, RH and LWT (at 3, 7, 10 and $15 \mathrm{~mm}$ from the lowest point of the sinus floor) were measured in NNT software in millimeters. Data were analyzed using the SPSS v22 software through independent-samples t-test, paired-samples t-test and ANOVA.

Results: In 150 assessed images, by increasing the wall distance from the floor, the mean sinus lateral wall thickness was increased $(\mathrm{p}=0.01)$. There was no relationship between gender and age with the sinus lateral wall thickness $(p>0.05)$. RH showed a significant relationship with LWT so that the higher the RH, the greater the LWT $(p<0.05)$. It was also observed that the mean LWT was $1.31 \pm 0.3 \mathrm{~mm}$ in the partial edentulism and $0.95 \pm 0.26 \mathrm{~mm}$ in the complete edentulism $(\mathrm{p}<0.05)$. The maximum thickness was found in the first molar and the minimum values were in the second premolar and the second molar.

Conclusion: Due to the impact of residual ridge height and type of edentulism on LWT and anatomical variations observed in the maxillary sinus, CBCT assessment is recommended before surgery such as sinus lifting in this area.
\end{abstract}

Keywords: Maxillary sinus, Dental implants, Cone-beam Computed tomography, Sinus floor augmentation

\section{Introduction}

One of the challenges associated with dental implant treatment in the edentulous posterior maxilla, is the ridge atrophy and pneumatization of the maxillary sinus following tooth extraction $(1,2)$. To overcome these problems, some solutions have been suggested, such as sinus lift, the use of short implants or tilted implants. The two last techniques have no favorable long-term survival due to strong occlusal forces in this area (3). For this reason, the sinus lift surgery accompanied by various bone grafts is regarded as the gold standard in bone reconstructive procedures of atrophic posterior maxilla $(4,5)$. Two common surgical procedures are crestal and lateral window techniques (6). Research has shown that the lateral window technique, especially in the case of minimal bone height, is associated with further predictable outcomes in terms of either result or safety (7). However, severe intraoperative bleeding, implant dislocation and sinus infections are the side effects of this technique (8). Sinus membrane

\section{Corresponding author:}

Associate Professor Dr. Farida Abesi, Dental Materials Research Center, Department of Oral \& Maxillofacial Radiology, Faculty of Dentistry, Babol University of Medical Sciences, Babol, Iran.

Tel: +98.9113132388, Email: f.abesi@yahoo.com

Received: June 16, 2017, Accepted: September 26, 2017, Published: December 2017

iThenticate screening: August 29, 2017, English editing: October 16, 2017, Quality control: November 01, 2017

This article has been reviewed / commented by three experts

(C) 2017 The Authors. This is an open access article under the terms of the Creative Commons Attribution-NonCommercialNoDerivs License, which permits use and distribution in any medium, provided the original work is properly cited, the use is non-commercial and no modifications or adaptations are made. 
perforation is the most common complication during sinus augmentation, with the incidence of $19.8 \%$. To avoid this problem, preoperative assessment of anatomic variations is very important, such as lateral wall thickness (LWT) (9, 10). The LWT assessments are applied for the decision making in surgical interventions such as the Caldwell-Luc, Le Fort I osteotomy, sinus lift with lateral window technique, fixation of maxillofacial fractures, placement of miniscrew in orthodontic treatment and diagnosis of chronic sinusitis. Studies show that in sinus lift surgery with lateral window technique, the increase in maxillary sinus lateral wall thickness causes more difficult and prolonged surgical procedure and an increased risk of sinus membrane perforation (11). In addition, the CBCT provides a reliable 3D diagnostic imaging technique for studying variations in the sinus area before surgery (9). Limited studies have investigated LWT with radiographic assessment, and the effect of edentulous ridge height on LWT is not fully understood $(9,11)$. Furthermore, no studies have been done in this regard among the population of northern Iran. This study aimed to assess the effect of edentulous region, residual ridge height $(\mathrm{RH})$, age, gender and type of edentulism (complete or partial edentulism) in the posterior maxilla on the lateral wall thickness of maxillary sinus among the population of northern Iran.

\section{Material and Methods}

\subsection{Research Design and Setting}

In this cross-sectional study conducted in 2016, 150 samples of the CBCT imaging archives of the Oral and Maxillofacial Radiology Clinic in Babol, Iran, were evaluated retrospectively. The patients were selected with relatively equal distribution in terms of gender ( 78 men and 72 women) with an age range of 20 to 60 years.

\subsection{Selection criteria}

Inclusion criteria were as follows: 1) maxillary sinus between premolars and molars as a result of missing one or more teeth (study regions included first premolar (PM1), second premolar (PM2), first molar (M1) and second molar (M2); 2) residual ridge height less than $10 \mathrm{~mm}$; ) the presence of adjacent or opposite teeth to edentulous region (in order to distinguish the location of edentulous ridge) and 4) visibility of maxillary sinus at least up to the height of $15 \mathrm{~mm}$ from the sinus floor. Exclusion criteria were 1) unclear or incomplete images due to scattering or other reasons; 2) residual ridge height over $10 \mathrm{~mm}$; 3) unclear location of edentulous ridge; 4) the existence of sinus pathology; 5) unclear border of edentulous ridge for reasons such as tooth extraction and 6) grafted maxillary sinus or the presence of implant.

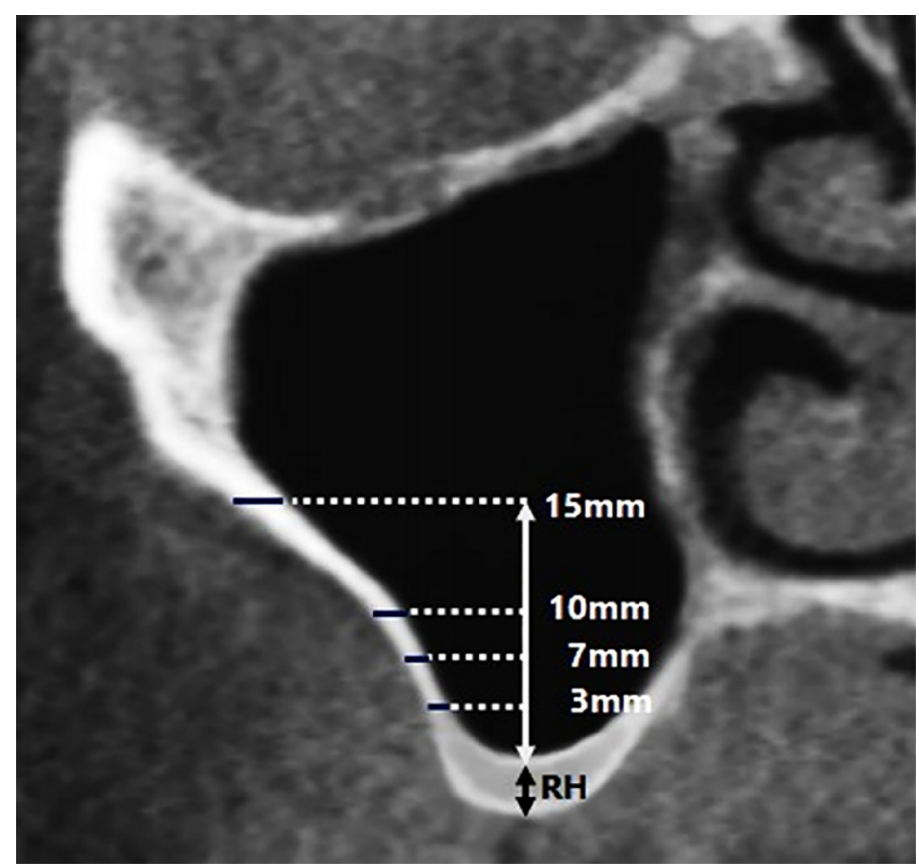

Figure 1. A view of residual ridge height and maxillary sinus lateral wall thickness in different distances

\subsection{Procedures and Measurement tool}

When both sinuses of a patient met inclusion criteria, only one of them would enter in the study. All images were provided through CBCT (GiANO, NewTom, Italy), operated at $90 \mathrm{kvp}, 9 \mathrm{~mA}$, exposure time of 18 seconds and 
voxel size of 75 microns. The slice interval and slice thickness of the device were $1 \mathrm{~mm}$ and $0.5 \mathrm{~mm}$, respectively. Ultimately, the CBCT images were inserted into a computer equipped with NNT software, 20 -inch monitor and resolution of $900 \times 1600$. For better image interpretation, the images were observed in a dark room. First, a periodontist studied the images in terms of exclusion criteria and the potential need for measuring, based on the patient's specific anatomy. Then, an oral and maxillofacial radiologist examined and measured the images. In NNT software, after adjusting the contrast and brightness to improve the quality of images, in the coronal section of CBCT image, the following measurements were carried out in millimeters (Figure 1):

1) Residual height $(\mathrm{RH})$ : the distance from the alveolar crest to the lowest point of the sinus floor

2) Lateral wall thickness (LWT): the perpendicular line at 3, 7, 10 and $15 \mathrm{~mm}$ from the lowest point of the sinus floor

The 15-mm level was chosen to be the level where the sinus augmentation surgery ends (9). The edentulous regions were divided to complete edentulous atrophic maxilla (without 5 posterior teeth) and partial edentulous atrophic maxilla (without any of the 5 posterior teeth) to determine the effect of the presence of teeth on LWT.

\subsection{Statistical analysis}

Data were analyzed using the IBM(C SPSS@ Statistics version 22 (IBM@ Corp., Armonk, NY, USA) through independent-samples t-test and paired-samples t-test (to compare the means of two independent and dependent groups), ANOVA (to compare the means of several independent groups) and repeated measures ANOVA (to compare the means of several dependent groups, repeated data); $\mathrm{p}<0.05$ was considered significant.

\section{Results}

In total, 78 male patients with the mean age of $46.19 \pm 9.71$, and 72 female patients with the mean age of $47.16 \pm 10.56$ were evaluated in the present study. According to the results obtained in this study, the mean RH was $6.87 \pm 2.19 \mathrm{~mm}$ in the premolar regions and 5.95 \pm 2.52 in the molar regions. The t-test revealed that this mean in the premolar regions was significantly higher than the molar regions $(p=0.02)$. The mean maxillary sinus lateral wall thickness (mm) with 95\% confidence interval based on the edentulous regions and measured height is shown in Table 1 and Figure 2.

Table 1. The mean lateral wall thickness $(\mathrm{mm})$ of maxillary sinus based on the edentulous region and measured height

\begin{tabular}{|l|l|l|l|l|}
\hline $\begin{array}{l}\text { Edentulous } \\
\text { region }\end{array}$ & $\begin{array}{l}\text { Lateral wall thickness } \\
3 \mathrm{~mm} \text { from sinus floor }\end{array}$ & $\begin{array}{l}\text { Lateral wall thickness } \\
7 \mathrm{~mm} \text { from sinus floor }\end{array}$ & $\begin{array}{l}\text { Lateral wall thickness } \\
10 \mathrm{~mm} \text { from sinus } \\
\text { floor }\end{array}$ & $\begin{array}{l}\text { Lateral wall thickness } \\
15 \mathrm{~mm} \text { from sinus } \\
\text { floor }\end{array}$ \\
\hline PM1 & $0.940(0.605-1.275)$ & $1.040(0.682-1.398)$ & $1.340(1.041-1.639)$ & $1.300(0.576-2.024)$ \\
\hline PM2 & $1.039(0.926-1.153)$ & $1.134(1.021-1.248)$ & $1.179(1.069-1.289)$ & $1.408(1.243-1.573)$ \\
\hline M1 & $1.068(0.994-1.143)$ & $1.269(1.187-1.352)$ & $1.469(1.378-1.560)$ & $1.766(1.660-1.873)$ \\
\hline M2 & $0.952(0.853-1.052)$ & $0.967(0.874-1.060)$ & $1.080(0.974-1.186)$ & $1.297(1.180-1.414)$ \\
\hline
\end{tabular}

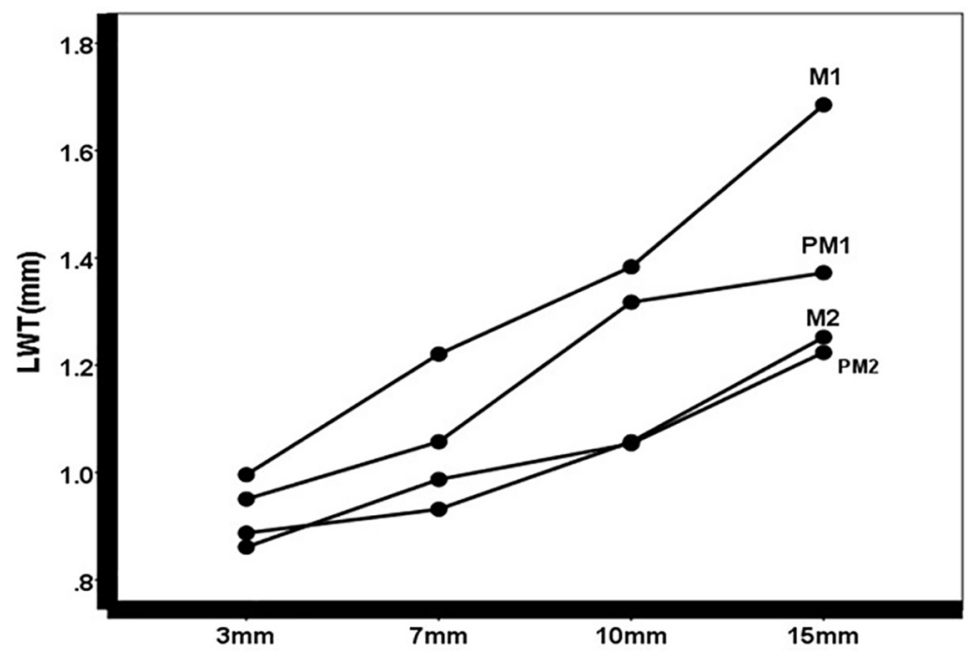

Figure 2. The mean lateral wall thickness $(\mathrm{mm})$ of maxillary sinus based on the edentulous region and measured height 
The lateral wall thickness $(\mathrm{mm})$ based on the edentulous region and type of edentulism has been presented in Table 2 and Figure 3. The repeated measures ANOVA revealed that the effects of height (from 3 to $15 \mathrm{~mm}$ of sinus floor) for LWT had significant difference and with increasing different heights, the mean LWT was increased $(\mathrm{p}=0.01$, $\mathrm{df}=3, \mathrm{~F}=3.24)$, (Table 1). There was no relationship between gender and sinus lateral wall thickness $(\mathrm{p}=0.79, \mathrm{df}=1$, $\mathrm{F}=0.06)$. The edentulous region $(\mathrm{p}<0.001, \mathrm{df}=3, \mathrm{~F}=7.05)$ and type of edentulism $(\mathrm{p}<0.001, \mathrm{df}=1, \mathrm{~F}=8.05)$ influence lateral wall thickness of maxillary sinus (Table 2). However, the interaction between the type of edentulism and the edentulous region was not significant ( $\mathrm{p}=0.90, \mathrm{df}=3, \mathrm{~F}=0.18$ ), (Figure 3 ). It was also found that the mean LWT in partial edentulism was more than in complete edentulism. The maximum thickness was found in the first molar and the minimum values were in the second premolar and the second molar (Figure 2). There was no relationship between age and the sinus lateral wall thickness ( $p>0.05)$, but RH showed a significant relationship with LWT so that the higher the RH, the greater the LWT $(\mathrm{p}<0.05)$. The gender and the type of edentulism did not cause a significant effect on the correlation between age and RH with LWT. The edentulous region showed no significant effect on the correlation between age and LWT. The correlation between RH and LWT was not significant in the PM1 and PM2 regions but was significant in the M1 and M2 regions.

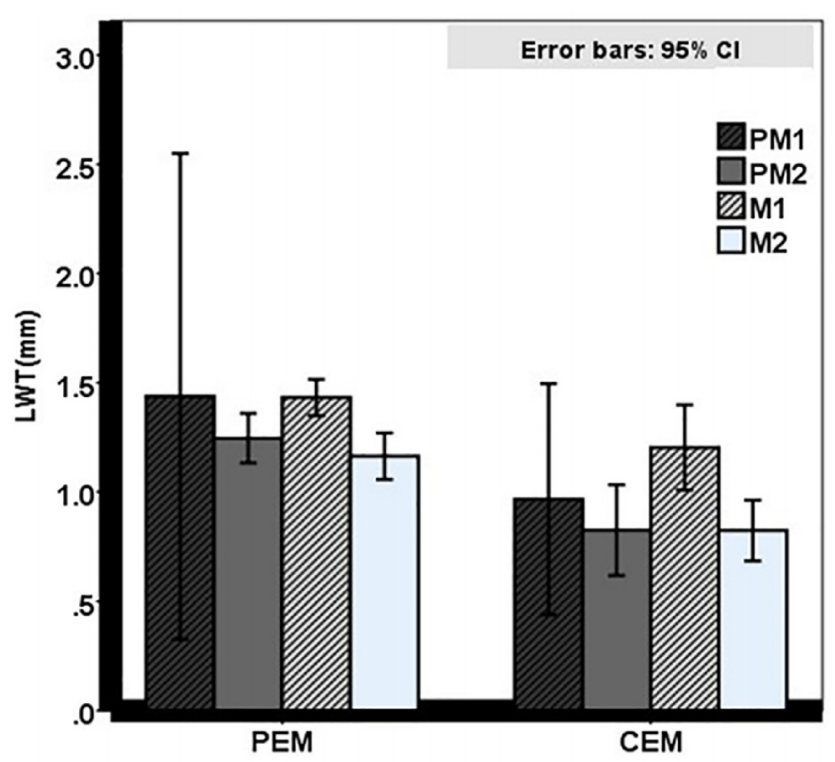

Figure 3. The lateral wall thickness $(\mathrm{mm})$ based on the interaction of edentulous region and type of edentulism

Table 2. The lateral wall thickness $(\mathrm{mm})$ based on the edentulous region and type of edentulism

\begin{tabular}{|l|l|l|}
\hline $\begin{array}{l}\text { Edentulous } \\
\text { region }\end{array}$ & Type of edentulism & $\begin{array}{l}\text { Mean } \pm \mathrm{S} \\
\mathrm{D}\end{array}$ \\
\hline \multirow{2}{*}{ PM1 } & Partial & $1.43 \pm 0.12$ \\
\cline { 2 - 3 } & Complete & $0.96 \pm 0.21$ \\
\hline PM2 & Partial & $1.24 \pm 0.32$ \\
\cline { 2 - 3 } & Complete & $0.82 \pm 0.16$ \\
\hline \multirow{2}{*}{ M1 } & Partial & $1.43 \pm 0.38$ \\
\cline { 2 - 3 } & Complete & $1.20 \pm 0.38$ \\
\hline M2 & Partial & $1.16 \pm 0.35$ \\
\cline { 2 - 3 } & Complete & $0.82 \pm 0.26$ \\
\hline
\end{tabular}

\section{Discussion}

In the present study, lateral wall thickness (LWT) of maxillary sinus in edentulous posterior maxilla was evaluated in patients with complete and partial edentulism. Dental implant placement is often restricted by sinus enlargement and the ridge atrophy in the posterior maxilla. Various sinus augmentation techniques have been introduced so far to tackle the problem, such as crestal technique and lateral window technique (12). The most frequently encountered surgical complication in lateral window approach is perforation of the Schneiderian membrane (8). To avoid this, preoperative assessment of anatomic variations by radiographic assessments is necessary and the knowledge of sinus anatomy, including lateral wall thickness, is the key to minimizing this complication (9). The results showed that by 
increasing the wall distance from the floor, the mean sinus lateral wall thickness was increased (from 3 to $15 \mathrm{~mm}$ of sinus floor). These findings correspond with the results of Monje et al. (9). Yang et al., in 2012, studied lateral wall thickness of maxillary sinus for sinus augmentation with the use of CT in edentulous patients. They considered the sinus floor as the reference point and measured LWT at 3,10 and $15 \mathrm{~mm}$ from sinus floor. It was found that the means of LWT were 1.69, 1.5, 1.77 and $1.89 \mathrm{~mm}$, respectively, from the first premolar to the second molar (13). The means of LWT in our study were a reported 0.96 (PM1), 0.82 (PM2), 1.2 (M1) and 0.82 (M2), which totally, are less compared to the amounts reported in the mentioned study. This difference could be due to failure to investigate the effect of the tooth extraction time on the wall thickness as well as racial differences. Given that increased LWT causes longer and more difficult open sinus lift surgery, knowing the LWT in different regions can help to select anatomic regions with lower thickness to reduce surgical complications such as sinus membrane perforation.

According to the present study, type of edentulism affects sinus lateral wall thickness. This means that the wall thickness is higher in the partial edentulism rather than complete edentulism, which is in line with the study of Monje et al. (9), but inconsistent with the result of Khajeh Ahmadi et al., which could be due to differences in measured heights from sinus floor for LWT (11). Khajeh Ahmadi et al., in 2014, evaluated the relationship between the lateral wall thickness of maxillary sinus and dental status using CBCT. They showed that gender and dental status had no significant effect on the lateral wall thickness of maxillary sinus. In addition, they stated that the maximum and minimum thickness of bone were respectively in the first molar and second molar regions (11). The present study also confirms this finding, so that the maximum thickness was in the first molar and the lowest values were observed in the second premolar and second molar. It seems that the reason for more thickness of lateral wall in the first molar region is the zygomatic buttress. However, Monje et al., Yang et al. and Neiva et al. believe that the wall thickness is increased gradually from the second premolar to the second molar; the second molar had the greatest thickness $(9,13,16)$. The results of Kang et al. in this regard, are at odds with recent studies (14). They believed that the more anterior the region, the thicker the LWT. These differences may be due to racial issues or internal bias because of CBCT device distortion (17). Similar to the study of Monje et al. (9), this study indicated that the RH has a positive relationship with the LWT, and LWT is greater in higher RH. Previous studies have indicated that the RH affects bone density in the maxillary sinus region and a thinner LWT can suggest a lower bone density (15). This finding could suggest to clinicians to take extra precautions during maxillary sinus floor augmentation through the lateral window technique in the severely atrophic posterior maxilla, due to the high probability of it being a soft and friable sinus lateral wall. Concerning ineffectiveness of gender on LWT, this study is consistent with recent studies $(9,11)$. Also, it is hypothesized that due to pneumatization of the maxillary sinus associated with aging, the LWT is thicker in younger people (9), but this hypothesis has not been confirmed in the studies of Monje et al., Yang et al. or Kang et al. $(9,13,14)$. According to their researches, the LWT and age have positive relationship with each other so that the thicker LWT was observed in the elderly. In this study, no significant relationship was found between age and the lateral wall thickness, which may be associated with racial issues or variations in studied reference points of the sinus floor.

\section{Conclusions}

The maxillary sinus lateral wall thickness gradually increases from 3 to $15 \mathrm{~mm}$ of the sinus floor. The residual ridge height and the type of edentulism influence the LWT, while age and gender have no effect on sinus lateral wall thickness. Therefore, according to the anatomical variations observed in the maxillary sinus, CBCT assessment is recommended before surgery such as sinus lifting in this area.

\section{Acknowledgments:}

The present study was based on a research plan (Ref. no. 9644316) in the form of a thesis for a degree in dentistry at Babol Faculty of Dentistry. The study was supported financially by the Deputy of Research of Babol University of Medical Sciences.

\section{Conflict of Interest:}

There is no conflict of interest to be declared.

\section{Authors' contributions:}

All authors contributed to this project and article equally. All authors read and approved the final manuscript. 


\section{References:}

1) van den Bergh JP, ten Bruggenkate CM, Disch FJ, Tuinzing DB. Anatomical aspects of sinus floor elevations. Clin Oral Implants Res. 2000; 11: 256-65. doi: 10.1034/j.1600-0501.2000.011003256.x. PMID: 11168217.

2) Gowrisankar $\mathrm{CH}$, Thanmayi P, Suprabath P, Hyandavi B. Correlation of maxillary sinus to the roots of maxillary posterior teeth and a review of literature. IJSR. 2017; 6(1): 506-15.

3) Chiapasco M, Casentini P, Zaniboni M. Bone augmentation procedures in implant dentistry. Int J Oral Maxillofac Implants. 2009; 24 Suppl: 237-59. PMID: 19885448.

4) Wallace SS, Froum SJ. Effect of maxillary sinus augmentation on the survival of endosseous dental implants. A systematic review. Ann Periodontol. 2003; 8(1): 328-43. doi: 10.1902/annals.2003.8.1.328. PMID: 14971260.

5) Ebru OK, Sebnem DI, Gokser C, Selcuk Y. Dental implant survival and success rate after sinus augmentation with deproteinized bovine bone mineral and platelet-rich plasma at one and five years: a prospective-controlled study. Biotechnology \& Biotechnological Equipment. 2017; 31(3): 594-9. doi: 10.1080/13102818.2017.1295818.

6) Summers RB. A new concept in maxillary implant surgery: the osteotome technique. Compendium. 1994; 15(2): 152, 154-6. PMID: 8055503.

7) Misch CE. Maxillary sinus augmentation for endosteal implants: organized alternative treatment plans. Int J Oral Implantol. 1987; 4(2): 49-58. PMID: 3269837.

8) Chan HL, Wang HL. Sinus pathology and anatomy in relation to complications in lateral window sinus augmentation. Implant Dent. 2011; 20(6): 406-12. doi: 10.1097/ID.0b013e3182341f79. PMID: 21986451.

9) Monje A, Catena A, Monje F, Gonzalez-García R, Galindo-Moreno P, Suarez F, et al. Maxillary sinus lateral wall thickness and morphologic patterns in the atrophic posterior maxilla. J Periodontol. 2014; 85(5): 676-82. doi: 10.1902/jop.2013.130392. PMID: 24304226.

10) Irinakis $T$, Dabuleanu V, Aldahlawi S. Complications During Maxillary Sinus Augmentation Associated with Interfering Septa: A New Classification of Septa. Open Dent J. 2017; 11: 140-50. doi: 10.2174/1874210601711010140. PMID: 28458730 , PMCID: PMC5388787.

11) Khajehahmadi S, Rahpeyma A, Hoseini Zarch SH. Association Between the Lateral Wall Thickness of the Maxillary Sinus and the Dental Status: Cone Beam Computed Tomography Evaluation. Iran J Radiol. 2014;11(1): e6675. doi: 10.5812/iranjradiol.6675. PMID: 24693302, PMCID: PMC3955858.

12) Esfahanizadeh N, Rokn AR, Paknejad M, Motahari P, Daneshparvar H, Shamshiri A. Comparison of Lateral Window and Osteotome Techniques in Sinus Augmentation: Histological and Histomorphometric Evaluation. J Dent (Tehran). 2012; 9(3): 237-46. PMID: 23119133, PMCID: PMC3484828.

13) Yang SM, Park SI, Kye SB, Shin SY. Computed tomographic assessment of maxillary sinus wall thickness in edentulous patients. J Oral Rehabil. 2012; 39(6): 421-8. doi: 10.1111/j.1365-2842.2012.02295.x. PMID: 22471834.

14) Kang SJ, Shin SI, Herr Y, Kwon YH, Kim GT, Chung JH. Anatomical structures in the maxillary sinus related to lateral sinus elevation: a cone beam computed tomographic analysis. Clin Oral Impl Res. 2013; 24 Suppl A100: 75-81. doi: 10.1111/j.1600-0501.2011.02378.x. PMID: 22150785.

15) Monje A, Monje F, González-García R, Suarez F, Galindo-Moreno P, García-Nogales A, et al. Influence of atrophic posterior maxilla ridge height on bone density and microarchitecture. Clin Implant Dent Relat Res. 2015; 17(1): 111-9. doi: 10.1111/cid.12075. PMID: 23607367.

16) Neiva RF, Gapski R, Wang HL. Morphometric analysis of implant-related anatomy in Caucasian skulls. J Periodontol. 2004; 75(8): 1061-7. doi: 10.1902/jop.2004.75.8.1061. PMID: 15455732.

17) Baumgaertel S, Palomo JM, Palomo L, Hans MG. Reliability and accuracy of cone-beam computed tomography dental measurements. Am J Orthod Dentofacial Orthop. 2009; 136(1): 19-25. doi: 10.1016/j.ajodo.2007.09.016. PMID: 19577143. 